\title{
PERSPECTIVE Equitable access to cell and gene therapies in South Africa: opportunities and hurdles
}

\author{
Candice Laverne Hendricks (D) ${ }^{1}$, Marco Alessandrini ${ }^{2}$ and Michael Sean Pepper (D) $^{1 凶}$ \\ (c) The Author(s), under exclusive licence to Springer Nature Limited 2021
}

Gene Therapy (2023) 30:180-186; https://doi.org/10.1038/s41434-021-00309-y

At present, more than 1200 cell and gene therapy (CGT) clinical trials are ongoing [1], and up to 50 such treatments are expected to be clinically available by 2030 [2]. A major contribution comes from the entry of chimeric antigen receptor (CAR) T-cell therapies into the market. These cells are genetically engineered to express a synthetic receptor that binds to antigens expressed on the surface of tumour or virally infected cells, resulting in T-cell activation and a re-directed immune response against the targeted cells [3]. AntiCD19 and anti-B-cell maturation antigen CAR T-cells have been shown to be effective against relapsed/refractory B-cell malignancies [3, 4] and multiple myeloma [5], respectively, which has led to recent approvals by regulators (Table 1) [6]. Other similar products, collectively referred to as ex vivo gene-modified cell therapies, have also been approved for the treatment and cure of rare monogenic disorders, including severe combined immunodeficiency due to adenosine deaminase deficiency [7], $\beta$-thalassaemia [8] and metachromatic leukodystrophy [9]. In addition, gene therapies-where therapeutic/corrective genes are delivered directly to patients-have also been approved for an inherited form of blindness and spinal muscular atrophy (Table 1). In South Africa, over and above being able to address these conditions, CGT approaches hold promise for potentially being able to cure human immunodeficiency virus (HIV), a condition that has severe health and socioeconomic consequences $[10,11]$. Although not a feature of the currently approved treatments, gene-editing toolsand in particular clustered regularly interspaced palindromic repeat (CRISPR) - are significantly advancing the development of CGT, allowing for an unprecedented repertoire of clinical applications $[12,13]$. Compared to small molecules and protein-based treatments (such as monoclonal antibodies), which require repeated administration to maintain a therapeutic effect, CGT treatments offer a solution in which a single dose could provide a durable therapeutic effect.

South Africa, rich in its cultural and ethnic diversity, mineral resources, and biodiversity, is characterised by a heavy burden of disease. Its history, centred on a legacy of institutionalised oppression and discrimination, has left in its wake the continuing socioeconomic challenge of inequality. According to the World Bank, 'South Africa remains a dual economy with one of the highest inequality rates in the world' [14] and there is no clearer measure of this than a Gini index of 63 in 2021 [15]. Based on this metric, it is the most unequal country in the world. Inequality in wealth is even higher: the richest $10 \%$ of the population held around $71 \%$ of net wealth in 2015 , while the bottom $60 \%$ held $7 \%$. Unemployment at $32.5 \%$ at the end of 2020 remains a key challenge. This has been exacerbated by the COVID-19 pandemic which saw the economy contract by $7 \%$ in 2020 [14]. The healthcare sector has not been spared from this inequality. The private health care sector, which serves $16 \%$ of the population $[16,17]$, is able to afford world-class therapies to insured patients, while the public sector, accessed by $84 \%$ of the population $[16,17]$, due to resource constraints, has to make decisions which ensure that the most beneficial treatments are prioritised for the largest number of patients. In addition, South Africa suffers from poor returns on human resource investments with up to $30 \%$ of locally trained doctors having emigrated [18].

Bearing the above in mind, the question arises as to how one might justify the provision of costly CGT to our patients. The Constitution of the Republic of South Africa (Chapter 2, section 27 [19]) enshrines the right of access to healthcare. The 'right' however does not lead to automatic 'access' because access is dependent on the availability of resources. Furthermore, resources can only be made available once the size of the problem to be solved has been determined. Two of the key areas requiring consideration are (a) increasing capacity and education around diseases requiring CGT, and (b) obtaining good quality data from which advocacy can be developed. The former requires strengthening outreach systems from regional and academic centres to primary health care clinics and district hospitals, as well as getting community health workers involved. The second factor, requiring data for advocacy, can then be built on the aforementioned system. Presently, we have no means of determining the size of the potential CGT market in South Africa due to the absence of a registry and no formal waiting lists. Although these systems are not yet in place, we do know anecdotally that the need for CGT in South Africa is large, and demand far exceeds supply. This is the result of limited capacity in terms of human resources and infrastructure but is compounded by the lack of sufficient/ appropriate legislation and government support, cultural sensitivities related to traditions and belief systems, limited funding opportunities, and insufficient education in all sectors of society (including the medical fraternity) which contribute to the fragility of public opinion. We believe it is important to consider the opportunities and challenges for CGT in our society in four distinct areas: health legislation, health economics, cost and capacity building.

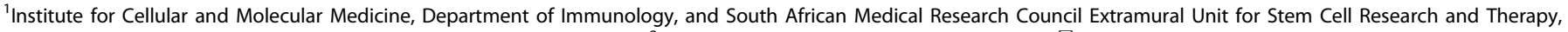
Faculty of Health Sciences, University of Pretoria, Pretoria, South Africa. ${ }^{2}$ Antion Biosciences SA, Geneva, Switzerland. ${ }^{凶}$ email: michael.pepper@up.ac.za 


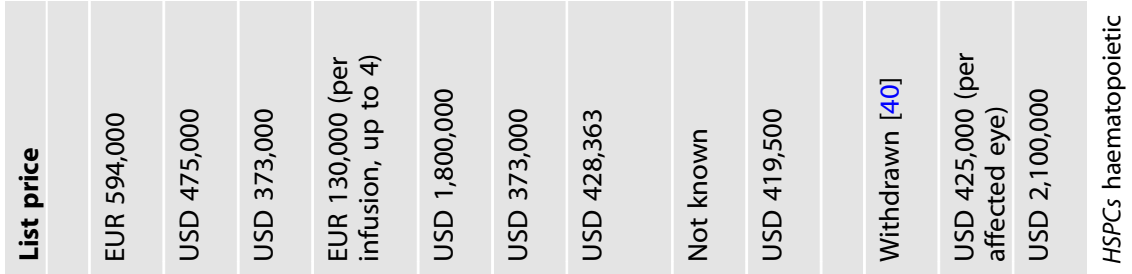
总

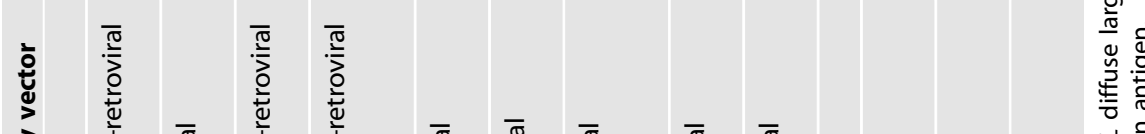

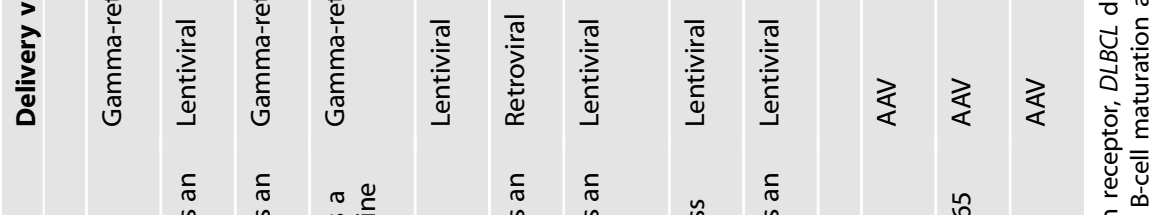

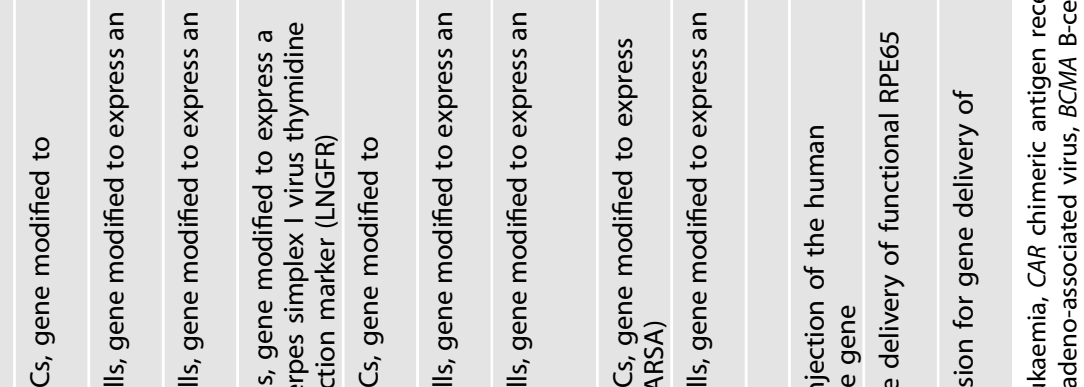

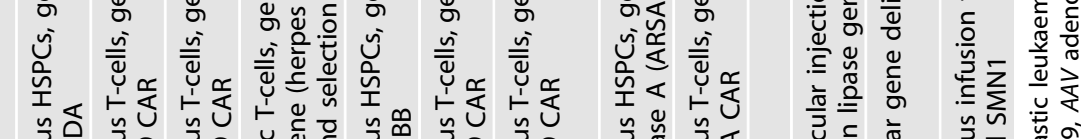

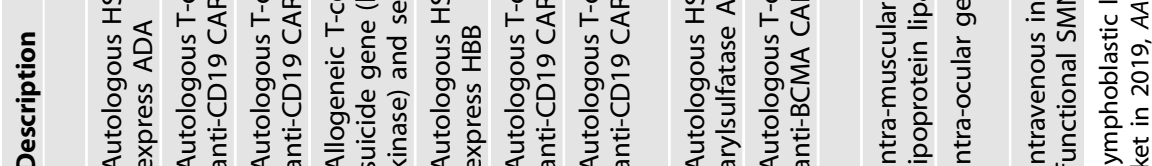

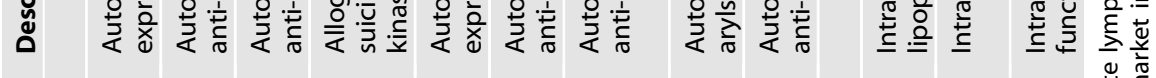

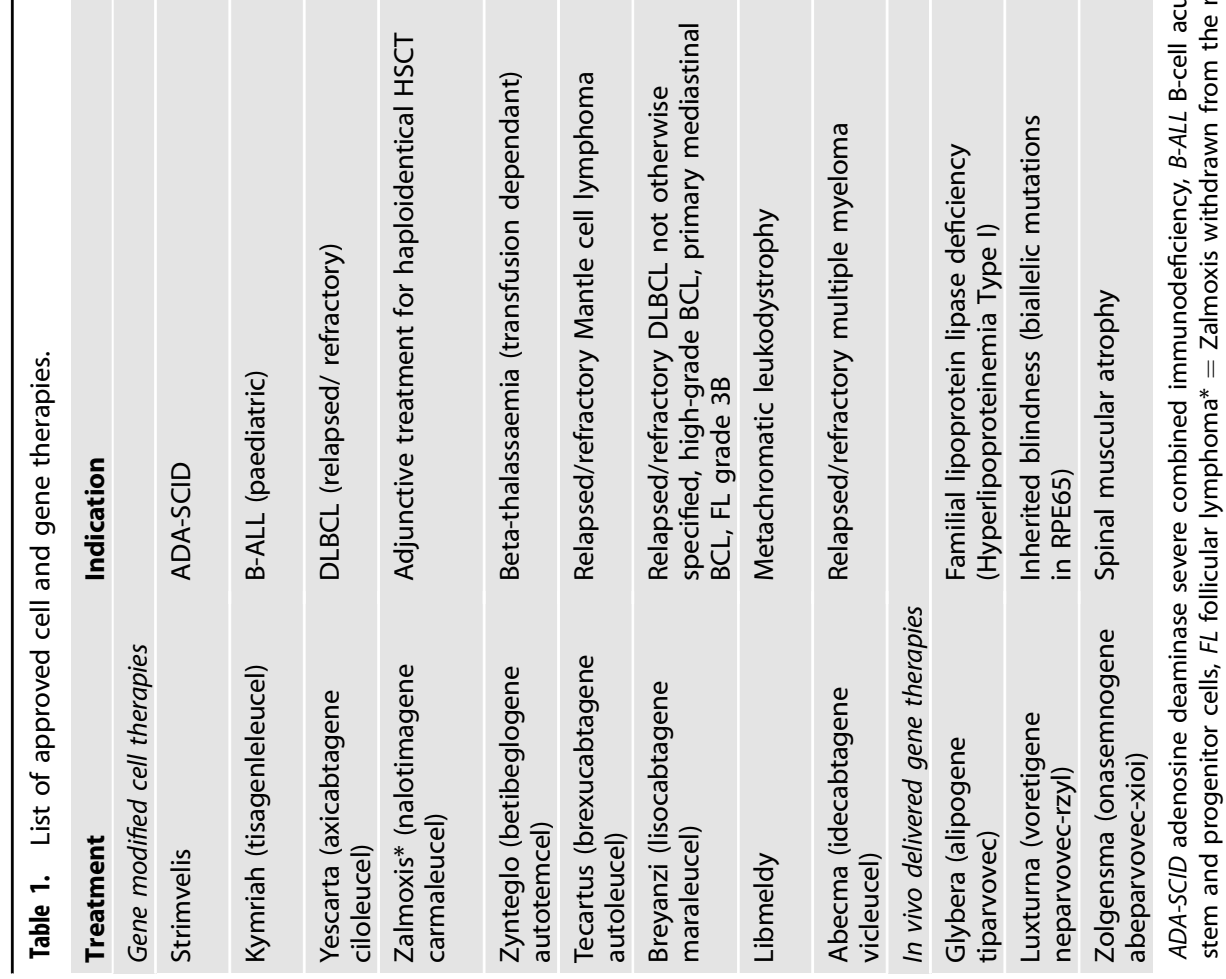




\section{HEALTH LEGISLATION}

The South African legislation makes provision for the registration of new drugs through the South African Health Products Regulatory Authority (SAHPRA). Legislation governing the manufacture or import of CGTs does not exist. The process of registration of genetically modified human biological materials requires expertise in balancing the need to apply advanced technologies for patient benefit with the need to provide a safe product of sufficient quality for the intended purpose. In addition, the objectives of having an adequate legislative environment include, amongst other things, the need to protect individuals from harmful and unethical practices and to respect an individual's right to determine how to use her/his own organs/ tissues/cells.

Given the inequalities inherent in access to advanced technologies, particularly with South Africa's dual healthcare system, Universal Health Coverage (UHC) may well be the way in which we bring this to the clinic. UHC is defined by the World Health Organization as a service where 'all people and communities can use the promotive, preventive, curative, rehabilitative and palliative health services they need, of sufficient quality to be effective, while also ensuring that the use of these services does not expose the user to financial hardship' [20]. The universal right to healthcare is based on the philosophical notion of distributive justice, which advocates for a just allocation/distribution of goods among members of society. In practice, however, access to and quality of healthcare are directly proportional to socioeconomic status, and quality of healthcare is adversely affected in a resource-poor setting. Nevertheless, the South African National Development Plan (NDP) clearly promotes the goal of 'universal equitable, efficient and quality healthcare' [17]. Provision must be made for all South Africans, allowing all members of society to benefit from advances in medical science. Legislation should however not be unduly restrictive in order to avoid stifling basic and clinical research and biotechnological innovation. The everchanging field of CGT requires a high degree of technical expertise and that advances in science and medicine are accommodated to ensure that legislation is accurate, appropriate and unambiguous. We have undertaken to detail the regulatory requirements for the initiation of a National legislative plan for CGT. Medical and Scientific advisory committees already exist in South Africa and once a clear plan is in place, it would fall on these committees to present this plan to the National Department of Health (NDoH), which once accepted would allow improved and safe access to these treatments.

\section{HEALTH ECONOMICS}

Healthcare resource allocation decisions generally aim to maximise healthcare delivery within the limits of available resources. Interventions must be clinically beneficial and cost-effective (or be dominant) relative to existing practice. A commonly used approach is a cost-effectiveness threshold where a reference incremental cost-effective ratio (ICER) serves as the basis against which an intervention can be considered to be 'good value for money' [21]. The ICER is usually expressed in cost per incremental gain in quality-adjusted life years (QALY) [22]. Of course, in considering the ICER, the resources of the country in question have to be acknowledged and a threshold set [23]. The WHO historically defined a cost-effectiveness threshold as a measure that is 'less than three times the national annual Gross Domestic Product (GDP) per capita, per disability-adjusted life years (DALY) avoided.' [23] This measure is now accepted to be outdated as it does not sufficiently rely on scientific measures to aid in decisionmaking [21]. In South Africa, this threshold should also take into account the possible effect on other health measures that may be compromised as a result of including the health measure in question [21]. Edoka and Stacey recently published a CE threshold that incorporates the 'health opportunity cost of health spending in $\mathrm{SA}^{\prime}$. Using a three-phase approach, they came up with a CE formula which links health spending to DALY's averted. In essence, the threshold found per DALY averted was ZAR 38465.46 (USD 2 539.96 [24]; the South African Rand is currently at just over ZAR 15.00 per USD 1.00 [24].), certainly less than one to three times the GDP per capita, which at the end of 2020 was just less than ZAR 50 000 [25].

Knowing the above, one must then acknowledge that in applying ICER to CGT, it is also important to consider its cost in comparison to the lifetime costs of continued treatment (e.g. in conditions like haemophilia A), chronic conditions to be managed (e.g. late effects from high dose chemotherapy) and the very real risk of death from the disease [26]. These therapies offer the hope of a cure for diseases, most of which have considerable morbidity. In addition, one would have to decide as a country whether to invest in those therapies that indeed give the highest return on investment. Cohen et al. recently compared seven CGT products with drugs or biological agents currently in use, using the ICER. Their results show CGT to be superior in average health gains [26]. The United States of America (USA), however, has long had a USD 50 000/QALY gained cost-effectiveness threshold, with many claiming it should be much higher [27]. This again bears testament to the fact that South Africa's resources may not be sufficient to justify these therapies at their present cost, even if we know patients stand to benefit.

\section{COST}

Cell and gene therapies will only be cost-effective if we manage to bring their costs down. The cost of CAR T-cell therapy ranges from USD 373,000 to USD 475,000, while gene therapies for monogenic disorders can exceed USD 2 million. Despite the vigour with which we may advocate for such therapies, the answer to whether we can access these treatments presently will persistently remain ' $\mathrm{No}^{\prime}$. The reason? They are unaffordable. This is especially so for patients in the public health care sector. This problem is of course not unique to South Africa. Two Indian biotech companies are developing CAR T-cells at a goal price reduction of nearly tenfold compared to current prices. The intended model is to decentralise the service and make use of local manufacturing and engineering expertise [4]. The long-term goal is to make these therapies available to other parts of the world. Even in the USA with significantly more resources, a recent budget-impact analysis for gene therapy in sickle cell disease highlighted the significant short-term financial impact of this therapy, highlighting the need to achieve a balance between cost-effectiveness and affordability [2]. Even well-resourced countries would have to explore and compare different funding models to make this a reality for all of their patients.

Beyond the need to access low-cost treatments from other countries lies the more imminent need to explore whether we cannot ourselves manufacture the products at a lower cost. A major challenge for the whole CGT field is the exorbitant cost of goods (CoGs) to manufacture these products. This is particularly true for the manufacture of viral vectors which are used for the production of all the gene and gene-modified cell therapies currently in the market, and most in clinical development. Viral vectors are 'disabled' viruses engineered to deliver the therapeutic genes to target cells, which then self-inactivate to prevent further propagation. In a recent report on patients with $\beta$-thalassaemia receiving either allogeneic HSCT or ex vivo gene-modified cell therapy, it was shown that although the recovery and level of complications were lower for the latter, the cost was still significantly higher [8]. Viral vector manufacturing accounted for $48 \%$ of the cost. These costs are anticipated to decrease as the competition among manufacturers increases and economies of scale come to bear. Exciting developments to facilitate off-the- 
shelf products, such as allogeneic CAR T-cells or inducedpluripotent stem cell (iPSC)-derived products, may provide for more affordable and sustainable models. In a genetically diverse country where African patients have a $<20 \%$ chance of finding an allogeneic donor for haematopoietic stem cell transplantation (HSCT) [28], these approaches are very promising. In this regard, numerous groups in the USA and Europe are developing novel allogeneic CAR T-cell therapies to treat many of the cancer indications that often require HSCT $[29,30]$. Furthermore, exciting developments for treating HIV with allogeneic CAR T-cells are also underway [31].

\section{CAPACITY BUILDING}

In order for a CGT service to be successful, one also needs to look beyond the 'how' to the 'when'. It is critically important not to leave this question unanswered until it is too late. Capacity building includes strengthening human resources, manufacturing and research. South Africa has a young and enthusiastic CGT community; however, more people need to be recruited into this highly specialised field. Cell therapy in South Africa is presently limited to HSCT; however, even this treatment modality has significant challenges, one of the most important being lack of suitable donors, particularly for patients of African and mixed-race ancestry [28]. The administration of gene therapy products for therapeutic purposes is absent in South Africa, although several clinical trials are underway. In particular, the University of the Witwatersrand (Wits) together with the South African Medical Research Council (SAMRC) has an Antiviral Gene Therapy Research Unit (AGTRU) focusing on gene therapy for Hepatitis B infection [32]. Professor Johnny Mahlangu, from the Haemophilia comprehensive care center at Wits, is actively involved in the Haemophilia A gene therapy landscape and contributed to a recently published 'global multidisciplinary consensus framework on haemophilia gene therapy' [33]. And at the Institute for Cellular and Molecular Medicine (ICMM) at the University of Pretoria, research on gene therapy for HIV is also underway [31, 34, 35]. Anecdotally, some patients who are able to afford it are travelling abroad for CAR T-cell and haemophilia gene therapy, and are then managed by local physicians on their return.

In order to strengthen human resource capacity, groups working on stem cells and CGT will need to recruit more students. This will certainly increase research capacity but will require funding. An initiative started in South Africa, jointly between the SAMRC, the NDoH and the Public health enhancement fund (PHEF) is the Bongani Mayosi National Health Scholars Programme (BM-NHSP) [36]. This initiative aims to train $1000 \mathrm{PhD}$ students over the course of 10 years. The focus areas are health and clinical research and this an ideal opportunity to capitalise on the gap in CGT expertise. The groups mentioned should have clear focus areas within their research mandate dealing with specific areas that would bring these therapies to the clinic. Critically, cosupervisors from international institutions where these therapies are being manufactured and administered should be actively sought and included in these research projects. Where possible, in collaboration with these international institutions, the students should spend time abroad at said institutions allowing for handson training. It would also be ideal to train more clinician-scientists who concurrently can do international fellowships, allowing for exposure to patient care following administration of CGT.

These north-south collaborations would provide advantages for all concerned. Many lower-to-middle income countries (LMIC) are well placed to provide highly sought after human material for research purposes, and in the case of southern Africa, the following contributing factors are well defined: (a) the extent of genetic diversity including some of the oldest living human populations; and (b) the extent and severity of both communicable and non-communicable diseases. In simplified terms, this can be seen as an important contribution of the under-resourced 'global south' to productive research collaborations. The 'global north' on the other hand provides much needed technological expertise for the analysis of this rich source of information. History however has taught us that the benefits derived from such collaborations are often skewed in favour of the 'north', and until recently limited attention has been given to the need for more appropriate sharing of these benefits. This can take many forms which do not necessarily need to be monetary. They do however require consideration of all the necessary ethical, legal and social implications prior to the collection of data [37]. This will include adequate informed consent, fair contracts and material transfer agreements, and adherence to local requirements regarding intellectual property protection, particularly if the research is publicly funded. In addition, the nature of the data generated and who will have access, as well as the reporting obligations of researchers, must be well defined. As a result of increased awareness and legal requirements, there appears to be a move away from the paternalistic nature of the relationships which have characterised many of these interactions in the past. There is already evidence of the power of these collaborations. The Bill and Melinda Gates Foundation together with the United States National Institutes of Health (NIH) will each contribute USD 100 million for gene therapy development in under-resourced countries [38]. The focus will be on clinical trials for sickle cell disease and HIV.

Whatever the strategy employed, it must remain clear that the success of such a programme will be directly proportional to the confidence of the people who will ultimately administer the product and care for the patients. The continued emigration of large numbers of trained staff is problematic, and a way needs to be found to retain staff by increasing professional opportunities and incentives back home. It is thus imperative that a concurrent infrastructure able to manufacture these therapies, and treatment centers able to administer them, be developed and built where required.

The manufacture of CGT therapy products is extremely complex, requiring hi-tech equipment, skilled staff, and good manufacturing practice-approved quality standards to ensure the provision of safe and effective treatments. This includes infrastructure for manufacturing both viral vectors and gene-modified cell products at scale. In the creation of a local facility, implementation of a fully integrated, scalable and versatile manufacturing platform would be ideal to fully capitalise on economies of scale and not to be reliant on offshore suppliers. The establishment of the facility should be centralised initially to ensure adequate regulatory oversight, training and commercialisation opportunities. In time, the inevitable move towards decentralisation of services and capacity to accommodate the provision of products for clinical trials and finally approved therapies must be provided for.

Increasing capacity cannot be achieved without government support. As it is the intention that these therapies are made available to both public and private patients, both sectors have to be sufficiently resourced. Autologous administration of ex vivo modified therapies, as an example, can only be administered in internationally accredited transplantation facilities. The State presently only has a handful of transplant centres and major upscaling of HSCT skills will be required in order for this goal to be reached. Expertise will have to be developed by doing regular autologous and allogeneic transplantations, which presently are in desperate need. From an administrative and governance perspective, the increased workload might be seen as a deterrent to productive collaborations. However, with well-coordinated efforts and a sensitivity to the needs of both parties, a workflow can be established that satisfies all of these needs. We believe that this will in the long run lead to sustainable partnerships which stand to benefit all of humankind. 


\section{THE WAY FORWARD}

Having highlighted important barriers and gaps in the South African system for the implementation of CGT, previously also eloquently enumerated by Arbuthnot et al. [39], we propose the following ways in which these difficulties could potentially be addressed. We also acknowledge that other LMIC who face similar challenges could adopt some of these guidelines and in turn also provide input that may enhance our approach:

- A dedicated South African Cell and Gene Therapy Society

- A CGT society will allow for all relevant stakeholders from academic and private institutions to collaborate towards a common goal; this could involve the creation of a de novo society or the transformation of an existing group.

- The society should appoint an Executive Committee who will oversee the functions of the society and provide guidance on its activities.

- Multiple sub-committees can have different functions, each contributing towards the overall vision of the society.

- The Executive Committee should have a clear relationship to the $\mathrm{NDoH}$ ministerial advisory committee (MAC), allowing for all CGT activities to come from one specific, unified committee to avoid duplication.

- Patient identification

- Registries: We propose that all diseases, but especially those with the defined potential for treatment or cure by gene therapy, establish registry committees as a matter of urgency. Where registries exist these should be strengthened and have a clear focus on data analysis with the aim of advocacy for gene therapy as part of their mandate. Ideally, these registry committees should either form part of the national CGT society or be acknowledged as a shared society to allow for data sharing.

- Outreach: All regional and academic centres that do not do outreach to smaller hospitals, should establish this as part of their clinical care. The centres should also, wherever possible, provide the referring institution with screening guidelines to better identify high-risk patients requiring referral.

- Human resource and research capacity

- Cell and Gene therapy projects: All laboratories in the country, currently working on stem cell and gene therapies where gene modification is involved, should work together to ensure that duplication is avoided and to prioritise the following:

- Projects should be created within each laboratory, according to the expertise that exists, to cover specific aspects of CGT that will answer specific questions e.g. regulatory/legislative matters; computational aspects which will allow for cost modelling amongst others; scientific projects dealing with gene therapy of existing diseases (this should be expanded to include CAR-T cell research, sickle cell disease, HIV gene therapy and others); biomedical engineering for the purposes of manufacturing these therapies.

- Once a clear mandate for each laboratory has been established, the appropriate international collaborators should be sought. Where possible, partner institutions should be established to ensure a constant bidirectional stream of students and fellows between institutions.

- Funding for these projects should be sought by applying for large grants e.g The Wellcome grant which encourages collaborations and whose aim is to fund multiple projects as part of a large overall vision of improving health outcomes.

- Clinical training: While scientific projects are undertaken, clinicians should also be trained in two different but overlapping ways:
- Clinician scientists: Clinicians in the disciplines dealing with patients who may benefit from CGTs should be encouraged to pursue scientific PhDs to expand their skills and understanding of the therapies they will be administering. Further to this, they will also be strengthened in their research capabilities and data analysis skills.

- Clinical fellows: Parallel to and overlapping with the above is the need for clinicians to train abroad in centres administering CGTs as part of their normal clinical activities. Examples would include HSCT fellowships or specific thrombosis and haemostasis fellowships for haemophilia (including gene therapy).

- Clinical trials: Once the appropriate legislative framework is in place, SA patients can be recruited actively onto international clinical trials. This is an important interim step before the capacity for local manufacture is in place.

- Manufacturing capacity

- The CGT society should form a sub-committee specifically dealing with the establishment of infrastructure and the human capacity for manufacture.

- Clinical facility

- It is important for those clinicians already involved in HSCT and gene therapy work, to work together at a national level to determine the best way forward for the administration of these therapies.

- Centralised facility: The most cost-effective way to bring these therapies to the clinic is likely initially to be a centralised facility/facilities in one province. In this facility, both public and private patients will have access to these therapies. Multiple private HSCT centers already exist and the decision would have to be made whether public patients could be accommodated in these centers at a fee. Those centers administering or planning to administer in vivo gene therapy could then decide to continue with their initiatives and create a national referral network for eligible patients at that center.

- Funding

- Models: Funding models created by e.g. actuaries would provide the projected cost for these therapies. It would be good to split the projection between ex vivo genemodified cell therapies and in vivo delivered therapies and do this on an annual basis. These projections should take into account the different cost components including staff, facilities, equipment etc. In vivo delivered therapies offer the advantage that they do not require the sophisticated in-patient facilities required for HSCT and may be more easily implemented from a clinical perspective. Costs here are usually lower and logistical and regulatory matters easier to manage than ex vivo CGTs. It will also be important to provide a model for the manufacture of allogeneic therapies using healthy donors or iPSCs. Once the projected cost is known it must be compared with the current cost of lifetime treatment for each disease in question e.g haemophilia, sickle cell disease and high-risk haematological malignancies. It is only once the difference in cost between the singleapplication treatment and lifetime treatment is known, that government can be approached. Knowing what is already being spent on these diseases is a major factor to consider in discussing potential curative therapies and the cost savings they may bring.

- Universal health care: The advantage of UHC is that the country's resources can be pooled to allow currently insured and uninsured patients to benefit equally. As described above, once the actual cost of the therapies has 
been determined, provision for this can be made as a budgetary item.

\section{- Government liaison}

- Government participation and funding, whether through UHC or otherwise, will be critical to ensure the sustainability of CGT in South Africa. The CGT society as mentioned earlier, through a MAC, would have to address the following matters in a detailed and systematic manner to ensure appropriate and responsible advocacy for the implementation of this service:

- Regulatory framework: For the initial part (which maybe years), the implementation of a regulatory framework for implementation of these therapies will have to be addressed, including the relevant ethical, legal and social implications.

- Data on the size of the problems to be solved will need to be presented. This data will be received through the existing registry networks. This will be important in light of the mentioned existing burden of disease. By ensuring that accurate data is presented, the government will be able to quantify the problem and prioritise it in line with existing health priorities.

- The plan for concurrent research and clinical human resource capacity must be in place.

- Types of gene therapies to be implemented and the particular advantages and disadvantages of each, as well as which facilities will be used for their administration, must have been decided on and presented.

- The financial models for both costing of the service as a whole and the comparison of current government expenditure for the disease categories must be provided. This costing will include infrastructure plans, as well as equipment, staff hire, quality control in addition to the actual manufacturing of the therapies. Funding should also be directed to research institutions for the development of CGT, which if patented can lead to commercialisation with wider reach and the creation of a funding stream.

\section{CONCLUSION}

Advances in the field of genome engineering mean that in our lifetimes, patients with incurable diseases are likely to benefit from a cure from a single-application procedure. This is an unprecedented advancement in medicine that will increase substantially in the next few years. It is important to ensure that all jurisdictions are in a position to take full advantage of these therapies and to grow local capacity to enable widespread access to all who require it. This goal will be achieved through advocacy and collaboration, and we must be innovative in our thinking as this is an ideal that can be achieved. Our patients deserve it.

\section{REFERENCES}

1. 2020: Growth \& Resilience in Regenerative Medicine-Alliance for Regenerative Medicine [Internet]. Alliance for Regenerative Medicine-Annual Report. 2020 [cited 2021 Jul 19]. https://alliancerm.org/sector-report/2020-annual-report/

2. Demartino $P$, Haag MB, Hersh AR, Caughey AB, Roth JA. A budget impact analysis of gene therapy for sickle cell disease: the medicaid perspective. JAMA Pediatr. 2021;97239:1-7. https://doi.org/10.1001/jamapediatrics.2020.7140

3. Pepper MS, Alessandrini M, Pope A, van Staden W, Green RJ. Cell and gene therapies at the forefront of innovative medical care: Implications for South Africa. $S$ Afr Med J. 2019;109:20-2. https://doi.org/10.7196/SAMJ.2019.v109i1.13425

4. Jayaraman K. Cut-price CAR-T cell therapies top India's biotech agenda. Nat Biotechnol. 2019;37:1388-9. https://doi.org/10.1038/s41587-019-0346-1

5. Munshi NC, Anderson LD, Shah N, Madduri D, Berdeja J, Lonial S, et al. Idecabtagene vicleucel in relapsed and refractory multiple myeloma. N Engl J Med. 2021;384:705-16. https://doi.org/10.1056/NEJMoa2024850
6. US Food and Drug Administration. Approved Cellular and Gene Therapy Products [Internet]. U.S. Food and Drug Administration. 2020 [cited2021 Mar 10]. https:// www.fda.gov/vaccines-blood-biologics/cellular-gene-therapy-products/ approved-cellular-and-gene-therapy-products

7. Kohn DB, Booth C, Shaw KL, Xu-Bayford J, Garabedian E, Trevisan V, et al. Autologous ex vivo lentiviral gene therapy for adenosine deaminase deficiency. $\mathrm{N}$ Engl J Med. 2021;384:2002-13. https://doi.org/10.1056/NEJMoa2027675

8. Coquerelle S, Ghardallou M, Rais S, Taupin P, Touzot F, Boquet $L$, et al. Innovative curative treatment of beta thalassemia: cost-efficacy analysis of gene therapy versus allogenic hematopoietic stem-cell transplantation. Hum Gene Ther. 2019;30:753-61. https://doi.org/10.1089/hum.2018.178

9. Libmeldy _ European Medicines Agency [Internet]. 2021 [cited 2021 Jul 19]. https://www.ema.europa.eu/en/medicines/human/EPAR/libmeldy

10. Alessandrini M, Krause K, Speck RF, Pepper MS. Transplantation of gene-modified haematopoietic stem cells: application and clinical considerations. S Afr Med J. 2019;109:65-70. https://doi.org/10.7196/SAMJ.2019.v109i8b.13910

11. Naidoo J, Fok E, Scholefield J. Therapeutic genome engineering: implications for South Africa. S Afr Med J. 2019;109:53 https://doi.org/10.7196/SAMJ.2019. v109i8b.13850

12. Nicholson SA, Pepper MS. CRISPR-Cas: revolutionising genome engineering. S Afr Med J. 2016;106:870 https://doi.org/10.7196/SAMJ.2016.v106i9.11061

13. Ren J, Zhao Y. Advancing chimeric antigen receptor $T$ cell therapy with CRISPR/Cas9. Protein Cell. 2017;8:634-43. https://doi.org/10.1007/s13238-0170410-x

14. The world bank. The world bank: South Africa Overview [Internet]. 2021 [cited2021 May 23]. https://doi.org/10.2752/bewdf/edch1079

15. World Population Review. Gini Coefficient by Country 2020 [Internet]. World Population Review. 2021 [cited 2021 Oct 12]. p. 1-8. https://worldpopulationreview.com/ country-rankings/gini-coefficient-by-country

16. Benatar S, Sullivan T, Brown A. Why equity in health and in access to health care are elusive: insights from Canada and South Africa. Glob Public Health. 2018;13:1533-57. https://doi.org/10.1080/17441692.2017.1407813

17. Gordon T, Booysen F, Mbonigaba J. Socio-economic inequalities in the multiple dimensions of access to healthcare: the case of South Africa. BMC Public Health. 2020;20:289 https://doi.org/10.1186/s12889-020-8368-7

18. Mayosi BM, Benatar SR. Health and Health Care in South Africa-20 Years after Mandela. N Engl J Med. 2014;371:1344-53. https://doi.org/10.1056/NEJMsr1405012

19. The Constitution of the Republic of South Africa, No 108 of1996 [Internet]. 1996. https://doi.org/10.2307/2186692

20. The World Health Organization. The World Health organization: Universal Health Coverage [Internet]. 2021 [cited 2021 May 23]. https://www.who.int/healthtopics/universal-health-coverage\#tab=tab_1

21. Edoka IP, Stacey NK. Estimating a cost-effectiveness threshold for health care decision-making in South Africa. Health Policy Plan. 2020;35:546-55. https://doi. org/10.1093/heapol/czz152

22. Cohen DJ, Reynolds MR. Interpreting the results of cost-effectiveness studies. J Am Coll Cardiol. 2008;52:2119-26. https://doi.org/10.1016/j.jacc.2008.09.018

23. Elliot M, Bruce L, Dhruv SK, James GK, Sydney R. WHO | Thresholds for the cost-effectiveness of interventions: alternative approaches [Internet]. Bull World Health Organ. 2015;93:65-132. 2471/BLT.14.138206

24. Exchange rates U. Dollar to South African Rand Exchange Rate Today, Live 1 USD to ZAR = 15.14 [Internet]. [cited 2021 Oct 28]. https://www.exchangerates.org.uk/ Dollars-to-South-African-Rands-currency-conversion-page.html

25. Stats SA GDP: Quantifying SA's economic performance in 2020 | Statistics South Africa [Internet]. Econ. Growth. 2020 [cited 2021 Jun 23]. http://www.statssa.gov. $\mathrm{za} / \mathrm{p}=14074$

26. Cohen JT, Chambers JD, Silver MC, Lin P-J, Neumann PJ Putting The costs and benefits of new gene therapies into perspective [Internet]. Health Affairs. 2019 [cited2021 Jun 3]. https://www.healthaffairs.org/do/10.1377/ hblog20190827.553404/full/

27. Neumann PJ, Cohen JT, Weinstein MC. Updating cost-effectiveness-the curious resilience of the $\$ 50,000$-per-QALY threshold. N Engl J Med. 2014;371:796-7. https://doi.org/10.1056/NEJMp1405158

28. Viljoen IM, Hendricks CL, Mellet J, Pepper MS. Perspectives on establishing a public cord blood inventory in South Africa. Cytotherapy. 2021. https://doi.org/ 10.1016/j.jcyt.2021.02.116

29. Caldwell KJ, Gottschalk S, Talleur AC. Allogeneic CAR cell therapy-more than a pipe dream. Front Immunol. 2021;11:1-12. https://doi.org/10.3389/ fimmu.2020.618427

30. Depil S, Duchateau P, Grupp SA, Mufti G, Poirot L. 'Off-the-shelf' allogeneic CAR T cells: development and challenges. Nat Rev Drug Discov. 2020;19:185-99. https://doi.org/10.1038/s41573-019-0051-2

31. Mlambo T, Roussel-Gervais A, Ilmjärv $S$, Šakić A, Salmon $P$, Myburgh R, Bredl $S$, Pepper MS, Krause KH, Speck, MIRF, Alessandrini M Development of an off-theshelf CAR T-cell therapy for HIV: a step towards a universally accessible advanced 
therapy. In: International Society for Cell and Gene Therapy (ISCT), New Orleans VIRTUAL Meeting. 2021.

32. Antiviral Gene Therapy Research Unit-Wits University [Internet]. [cited 2021 Oct 18]. https://www.wits.ac.za/agtru/

33. Pierce GF, Pasi KJ, Coffin D, Kaczmarek R, Lillicrap D, Mahlangu J, et al. Towards a global multidisciplinary consensus framework on haemophilia gene therapy: report of the 2nd World Federation of Haemophilia Gene Therapy Round Table. Haemophilia. 2020;26:443-9. https://doi.org/10.1111/hae.13971

34. Myburgh R, Ivic S, Pepper MS, Gers-Huber G, Li D, Audigé A, et al. Lentivector knockdown of CCR5 in hematopoietic stem and progenitor cells confers functional and persistent HIV-1 resistance in humanized mice. Kirchhoff $F$, editor. J Virol. 2015;89:6761-72. https://doi.org/10.1128/JVI.00277-15

35. Barmania F, Pepper MS. C-Cchemokine receptor type five (CCR5): an emerging target for the control of HIV infection. Appl Transl Genomics. 2013;2:3-16. https:// doi.org/10.1016/j.atg.2013.05.004

36. RFA_ Bongani Mayosi National Health Scholars Programme, 2022 Enrolment South African Medical Research Council [Internet]. 2021 [cited 2021 Oct 18]. https://www.samrc.ac.za/request-for-applications/rfa-bongani-mayosi-nationalhealth-scholars-programme-2022-enrolment

37. Pepper MS, Dandara C, de Vries J, Dhai A, Labuschaigne M, Mnyongani F, et al. ASSAf consensus study on the ethical, legal and social implications of genetics and genomics in South Africa. S Afr J Sci. 2018;114:11-3. https://doi.org/ 10.17159/sajs.2018/a0302

38. Hargreaves B Partnership to create affordable gene therapies [Internet]. 2019 [cited 2021 Oct 18]. https://www.biopharma-reporter.com/Article/2019/10/24/ Partnership-to-create-affordable-gene-therapies

39. Arbuthnot P, Maepa MB, Ely A, Pepper MS. The state of gene therapy research in Africa, its significance and implications for the future. Gene Ther. 2017;24:581-9. https://doi.org/10.1038/gt.2017.57
40. EMA. Glybera | European Medicines Agency [Internet]. European Medicines Agency. 2012 [cited 2021 Oct 18]. https://www.ema.europa.eu/en/medicines/ human/EPAR/glybera

\section{AUTHOR CONTRIBUTIONS}

$\mathrm{CLH}, \mathrm{MA}$ and MSP all contributed equally to the concept, preparation and editing of the paper.

\section{FUNDING}

This work was funded by the South African Medical Research Council (Extramural Unit for Stem Cell Research and Therapy) and the University of Pretoria through the Institute for Cellular and Molecular Medicine.

\section{COMPETING INTERESTS}

The authors declare no competing interests.

\section{ADDITIONAL INFORMATION}

Correspondence and requests for materials should be addressed to Michael Sean Pepper.

Reprints and permission information is available at http://www.nature.com/reprints

Publisher's note Springer Nature remains neutral with regard to jurisdictional claims in published maps and institutional affiliations. 